\title{
MODELOS ANIMALES EN EL ESTUDIO DEL GLAUCOMA: PASADO, PRESENTE Y FUTURO
}

\section{ANIMAL MODELS IN THE STUDY OF THE GLAUCOMA: PAST, PRESENT AND FUTURE}

\author{
VECINO $\mathrm{E}^{1}$
}

Estudios realizados con modelos animales nos han ayudado a entender los mecanismos de la formación y evacuación del humor acuoso, así como el mantenimiento de la homeostasis de la presión intraocular. A menudo, estos estudios han conducido al conocimiento de la etiología de los glaucomas y el desarrollo de terapias. A través de la diversidad de las estructuras y la función de los ángulos de drenaje específico de cada especie animal, los estudios comparados han ampliado los conceptos, por otra parte limitados, de la enfermedad del segmento anterior humano. Por su destino compartido en el desarrollo de la hipertensión y del glaucoma espontáneo o inducido, los modelos animales han permitido lograr estrategias terapéuticas que de otra forma habrían sido imposibles.

A lo largo del tiempo se han descrito diversos modelos de glaucoma espontáneo en distintos animales. A principios de los años 60 el grupo de Kolker describió un grupo de conejos albinos de la raza Neozelandesa que, de forma natural, mostraban una alteración en el desarrollo de la malla trabecular (1). La descripción anatómica de las alteraciones que presentaban -una reducción en el número de lamelas, aumento en el espacio intercelular entre las lamelas, vacuolación de las células endoteliales y fragmentación de la lámina basal- permitieron emitir la hipótesis de que la causa de la elevación de la presión intraocular podría ser la reducción en el soporte estructural de la trabécula. Además, se detectaron niveles elevados de fibrina en el humor acuoso, proponiendo que esta fibrina podría obstruir la evacuación del humor acuoso, y por tanto, elevar la presión intraocular. Sin embargo, la ausen- cia de lámina cribosa y la mielinización parcial de las células ganglionares de la retina, junto con la existencia de un prominente saco vasculoso, han hecho del conejo un modelo animal no muy adecuado para el estudio de las alteraciones en la retina o su vascularización en el glaucoma.

A finales de los años 60 las observaciones realizadas por oftalmólogos veterinarios condujeron a la descripción de perros con glaucoma espontáneo, descubriendo la existencia de ciertas razas (beagles, cocker y baset hounds) más sensibles a dicha patología. Pero así como en el caso de los conejos el tipo de glaucoma es de ángulo abierto, en el caso de los perros se trata de glaucoma de ángulo cerrado. En el caso de la raza cocker, los perros afectados desarrollan el glaucoma desde edades muy tempranas, en el caso de los beagles y basset hounds el proceso es progresivo, manifestándose entre los $6 \mathrm{y}$ los 12 meses de edad (2). En los beagles, se trata de una herencia autosómica recesiva simple y durante el estado pre-glaucomatoso se detecta un incremento de la presión intraocular y la gonioscopía revela ángulo abierto sin otras anormalidades; sin embargo, con la progresión del glaucoma el ángulo comienza a cerrarse después de uno a dos años. Las presiones crónicas de entre 30 y $40 \mathrm{mmHg}$ pueden tener elevaciones transitorias de hasta 60 y 80 $\mathrm{mmHg}$, induciendo la excavación patente de la cabeza del nervio óptico. En estos animales el glaucoma es susceptible de tratamiento farmacológico con varias medicinas utilizadas en humanos, siendo eficaz el tratamiento farmacológico con pilocarpina, epinefrina, acetazolamida y diclorfenamida.

\footnotetext{
1 Doctora en Biología. Catedrática de Biología Celular e Histología. Facultad de Medicina. Universidad del País Vasco. Leioa. Vizcaya. España. E-mail: elena.vecino@ehu.es

Este editorial es parte de la conferencia impartida por la Dra. Vecino en Brasil dentro del congreso de Neurociencias de América Latina-CaribePenínsula Ibérica (Neurolatam 2008), titulada «What can we learn from animal models in glaucoma?».
} 
En 1993 se describió por primera vez una colonia de macacos, localizada en Cayo Santiago. En nueve familias de estos macacos se ha descrito una herencia materna con una incidencia del $40 \%$ de elevación de la presión intraocular. En los animales afectados se ha descrito una pérdida de células ganglionares de la retina, excavación del nervio óptico y evidencia electrofisiológica de daño en el campo periférico de la retina (3).

Recientemente la aparición del ratón $\mathrm{DBA} / 2 \mathrm{~J}$, que desarrolla un aumento paulatino de la PIO induciendo la muerte de las células ganglionares (4), ha generado gran número de estudios con el fin de establecer la existencia de homologías con algún tipo de glaucoma en humanos. La elevación de la presión intraocular en estos animales aparece a la edad de 6 meses y su presión se mantiene crónicamente elevada hasta su muerte. Sin embargo, existen factores como son el reducido tamaño del globo ocular o la ausencia de lámina cribosa que limitan el uso de estos animales para ciertos estudios.

Estos modelos animales con elevación crónica de la presión intraocular de forma espontánea son ideales para el estudio de las causas de esta patología, sin embargo, a excepción de los ratones DBA/2J, los animales con glaucoma espontáneo son difíciles de obtener de forma comercial, y aún más difícil obtener grupos con un estadío similar de la patología. Por ello y con el fin de facilitar la experimentación y el desarrollo del conocimiento del glaucoma, a lo largo de la historia se han desarrollado modelos de glaucoma experimental inducido. En algunos casos, la inducción del glaucoma experimental fue anterior a la descripción de un modelo espontáneo de glaucoma, como ha sido el caso del desarrollo del modelo de glaucoma por láser en primates. Así, en el año 1974 Gaasterland y sus colaboradores desarrollaron el primer modelo de láser en primates, que ha sido ampliamente utilizado con posterioridad por otros autores. Al igual que en humanos, tras realizar una trabeculoplastia con láser de argón, se produce una elevación transitoria de la presión intraocular que parece ser producida por la formación de mallas de fibrina que obstruyen los espacios de la malla trabecular. Sin embargo, en todos los modelos de glaucoma en monos siguiendo este procedimiento, se produce una midriasis fija, probablemente debida al daño en los nervios ciliares. Además se producen fluctuaciones muy grandes en las presiones intraoculares $\mathrm{y}$, en la mayoría de los casos, son necesarias varias sesiones de láser para obtener elevaciones continuas de las presiones, lo que produce inflamaciones severas en el globo ocular y alteraciones en la trabécula que imposibilitan estudios farmacológicos dirigidos a esta zona. Si bien existen estos inconvenientes en este modelo experimental del glaucoma, los primates han sido utilizados muy ampliamente para mejorar los indicadores clínicos de daños iniciales en el nervio óptico en glaucoma.

El gran avance, desde mi punto de vista, en el estudio del glaucoma ha venido impulsado por el desarrollo de modelos de glaucoma en ratas. Estos animales son mucho más económicos y su mantenimiento más accesible, además de causar problemas éticos de menor calado. En 1995 el grupo del Dr. Sharma desarrolló el modelo de cauterización de las venas epiesclerales en la rata como modelo de elevación crónico de la presión intraocular (5). Este modelo permite mantener íntegra la estructura de la trabécula no afectando tampoco el nervio ciliar, como sucede en el modelo de láser. Además, la presión intraocular se puede mantener elevada hasta 6 meses, lo que para la vida de la rata supone la cuarta parte de su existencia. El desarrollo de este modelo animal ha permitido el ensayo farmacológico de distintas combinaciones y concentraciones de fármacos hipotensores y neuroprotectores como paso previo al estudio en animales mayores antes de los ensayos clínicos. Las ratas en este caso están suponiendo una gran ayuda para los humanos en el estudio de terapias antiglaucomatosas. Fue el mismo grupo del Dr. Sharma, quien en el mismo año describió por primera vez que las células ganglionares de la retina en el glaucoma morían siguiendo un programa de muerte, denominado apoptosis (6). En este mecanismo están implicadas las caspasas, moléculas que al ser inhibidas en cierto momento del proceso del daño rescatan a las células de su muerte y por lo tanto las neuroprotege. A pesar de ser la rata un modelo animal que permite su utilización en gran número, con el fin de realizar pruebas farmacológicas, el tamaño de su ojo limita su uso en ciertos aspectos oftalmológicos. Por ello, nuestro grupo de investigación desarrolló un modelo de glaucoma en el cerdo y minicerdo, utilizando el mismo sistema de cauterización de venas epiesclerales (7). Ello nos ha permitido realizar estudios vasculares y retinianos utilizando la misma tecnología empleada en la oftalmología en humanos.

El avance en el tratamiento del glaucoma ha venido asociado al desarrollo de modelos animales al 
igual que el avance en el diagnóstico del glaucoma ha venido acompañado del avance tecnológico. Esperemos que en los próximos años podamos contar con un avance exponencial en el estudio de la prevención y la neuroprotección en glaucoma, utilizando los modelos animales desarrollados en los últimos años.

\section{BIBLIOGRAFÍA}

1. Kolker AE, Moses RA, Constant MA, Becker B. The development of glaucoma in rabbits. Invest Ophthalmol 1963; 2: 316-321.

2. Gelatt KN, Peiffer RL Jr, Gwin RM, Gum GG, Williams LW. Clinical manifestations of inherited glaucoma in the beagle. Invest Ophthalmol Vis Sci 1977; 16: 1135-1142.
3. Dawson $W W$, Brooks DE, Hope GM, Samuelson DA, Sherwood MB, Engel HM, et al. Primary open angle glaucoma in the rhesus monkey. Br J Ophthalmol 1993; 77: 302-310.

4. John SW, Smith RS, Savinova OV, Hawes NL, Chang B, Turnbull D, et al. Essential iris atrophy, pigment dispersion, and glaucoma in DBA/2J mice. Invest Ophthalmol Vis Sci 1998; 39: 951-962.

5. Shareef SR, García-Valenzuela E, Salierno A, Walsh J, Sharma SC. Chronic ocular hypertension following episcleral venous occlusion in rats. Exp Eye Res 1995; 61: 379-382.

6. García-Valenzuela E, Shareef S, Walsh J, Sharma SC. Programmed cell death of retinal ganglion cells during experimental glaucoma. Exp Eye Res 1995; 61: 33-44.

7. Ruiz-Ederra J, García M, Hernández, M, Urcola H, Hernández-Barbáchano E, Araiz J, et al. The pig eye as a novel model of glaucoma. Exp Eye Res 2005; 81: 561-569. 